\title{
Antioxidant status, nutrition facts, and sensory of spinach extract fortified wet noodles
}

\author{
*Susanti, S., Dwiloka, B., Bintoro, V.P., Hintono, A., Nurwantoro, N. and Setiani, B.E. \\ Food Technology Division, Department of Agriculture, Faculty of Animal Science and Agriculture \\ Diponegoro University, Semarang, Indonesia
}

\author{
Article history: \\ Received: 8 February 2021 \\ Received in revised form: 23 \\ March 2021 \\ Accepted: 29 May 2021 \\ Available Online: 28 \\ December 2021
}

\section{Keywords:}

Antioxidants,

Nutrition,

Spinach extract,

Wet noodle

DOI:

https://doi.org/10.26656/fr.2017.5(6).027

\begin{abstract}
Healthy food has been a lifestyle trend in modern society since the last decades. Vegetable noodles as an alternative healthy food are often consumers' choices considering that noodles are a favourite food today. This study aims to get more insight into the effect of spinach extract (SE) fortification on noodle dough toward antioxidant status, nutrition facts, and the sensory of wet spinach noodles (WSN) produced. The dough of wet noodle samples was treated by 4 different concentrations of SE fortification of $0,0.4,4.0$, and 40 $\mathrm{mg} / \mathrm{mL}$ in which for each treatment was quintuple. Results showed SE fortification had a significant effect on antioxidant status, some nutrient composition (protein, sugar, cholesterol, energy amount, iron, magnesium, and vitamin C), and sensory characteristics of the wet noodle. WSN with rich in antioxidants, low calories, and favoured by panellists was obtained at the optimum concentration of $4 \mathrm{mg} / \mathrm{mL}$. Thus, SE was potential as food fortificant for developing WSN as a promising functional food product in the future.
\end{abstract}

\section{Introduction}

Currently, noodles have become a favourite food source for carbohydrates in almost all stratum of society because of their savoury taste, chewy texture, ease to serve, and can be further processed into a variety of delicious menus (Errington et al., 2014). Noodle consumption especially its instant packaging has increased more than other fast foods such as pizza or burgers for the last decades (Hou, 2010).

Instant noodles are not always good for health even though rich in flavour. This is due to the imbalance in nutritional composition and the presence of some food additive ingredients (Gulia et al., 2014). Frequent and excessive consumption of instant noodles in everyday life is a high risk to the body health such as obesity, metabolic diseases, and other digestive disorders (Shin and Kang, 2017; Chung et al., 2010). In order to produce noodles that are relatively healthy and balanced in the aspect of nutrition, especially for a period of body growth and development, it is necessary to provide additional vegetables in the manufacturing process. With the addition of vegetables, it is expected that noodles can become vitamin-rich food products. According to the healthy lifestyle, vitamins in food can play a role as a free radical binding antioxidant that prevents the body cells damage (Ashor et al., 2016). Unfortunately, most people, especially children and adolescents do not like vegetables as a supplement to their diet (O'Dea, 2003). Therefore, it is necessary to make efforts to process vegetables-rich foods that are easily accepted and favoured by children.

Spinach (Amaranthus spp) has chemical components that are beneficial to health such as proteins, fats, carbohydrates, iron, vitamins A, B, and C (Roberts and Moreau, 2016). Spinach is also a good source of antioxidants for the body because spinach extract is known to contain components of flavonoids, phenolic, carotenoids, and vitamin C (Bergman et al., 2001; Babu et al., 2018; Naznin et al., 2019). It is known that spinach has very strong antioxidant activity with a small IC50 $(\leq 50 \mu \mathrm{g} / \mathrm{mL})$ which is about $29.67 \mu \mathrm{g} / \mathrm{mL}$ (Molyneux, 2004).

The utilization of spinach as food fortification was limited to its role as a fibre source so far, while its property as antioxidants have not been much developed. With extraction technology, this study added spinach extract (SE) into the noodle dough to produce the antioxidant-enriched noodle which is beneficial to health. Previous studies reported the application of spinach paste as a flour substitution in the vegetable instant noodle making process (Ramu et al., 2016). Spinach paste noodles contain low carbohydrates with 
physical and sensory characteristics that could be well accepted by panellists (Ramu et al., 2016). In this study, SE will be applied as food fortificant to produce healthy and delicious vegetable noodle products. Therefore, this study aims to get more insight into the effect of SE fortification on noodle dough toward antioxidant status, nutrition facts, and the characteristics of wet spinach noodles produced. It is expected that spinach noodles produced in this study have potency as functional noodles that is acceptable in society as commercial functional food product someday.

\section{Materials and methods}

\subsection{Preparation of spinach extract}

Preparation of spinach leaf extract consisted of leaf drying, leaf powdering, maceration process, and extract evaporation (Figure 1). Fresh spinach leaves (Amaranthus spp) purchased from the local market was dried at the temperature of $40-45^{\circ} \mathrm{C}$ for $4-5 \mathrm{hrs}$. After powdering, the sample was macerated by $70 \%$ of methanol in the ratio of 1: 5 . The extract solution was shaken every 2 hrs for 2 days then filtered in order to get the crude methanol extract. The filtrate was evaporated by using a vacuum rotary evaporator at $40^{\circ} \mathrm{C}$. The concentrated extract was stored in a sealed vial covered with aluminium foil and kept in the refrigerator for later application.

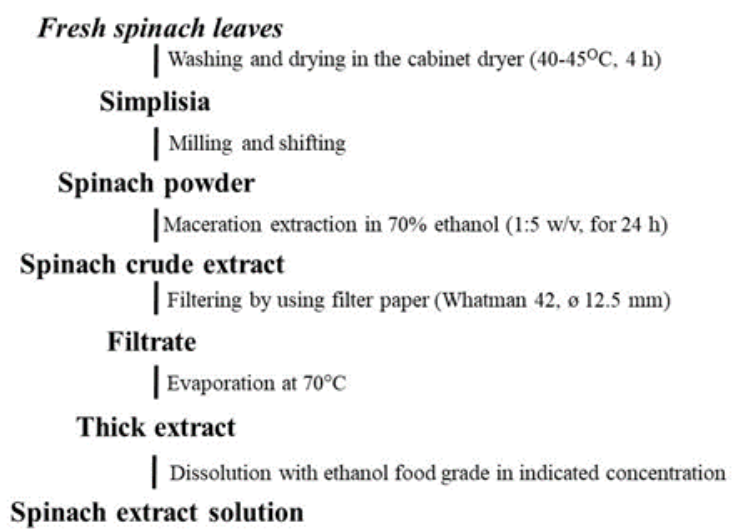

Figure 1. Flowchart diagram of spinach extraction

\subsection{Preparation of wet spinach noodles}

Wet spinach noodles (WSN) was prepared as described in Figure 2. First, wheat flour $(1 \mathrm{~kg}), 2$ chicken eggs, a teaspoonful of salt, sodium carbonate $(0.6 \%)$, water $(200 \mathrm{~mL})$, and spinach extract (SE) in different levels of concentration $(0,0.4,4$, and $40 \mathrm{mg} / \mathrm{mL})$ were mixed and kneaded manually. The Dough was moulded into noodles by using a pasta machine (Marcato Atlas 150 , Italy) according to the manufacturer instruction. The wet noodle product was boiled and then packaged for further analysis.

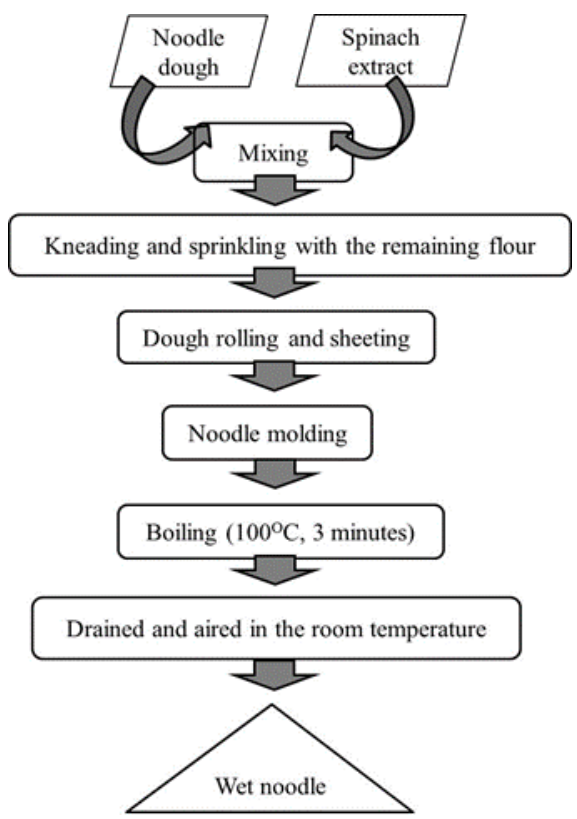

Figure 2. Flowchart diagram of WSN production

\subsection{Experimental analysis}

\subsubsection{Antioxidant status of wet spinach noodles}

Antioxidant activity was determined by the 1,1diphenyl-2-picrylhydrazyl (DPPH) Method (Molyneux, 2004). The sample solution was prepared by dissolving 1 $\mathrm{g}$ of spinach noodle in the methanol solvent. Then samples solution in different volumes $(30,60,90,150$ $\mu \mathrm{L}$ ) were added into test tubes and mixed with $3.8 \mathrm{~mL}$ DPPH $\mu \mathrm{M}$. Mixture solutions were centrifuged and left for 30 minutes in the dark and optical density was measured at $515 \mathrm{~nm}$ using a UV-VIS spectrometer (Specord $囚 P l u s$, Analytic Jena, Germany). The optical density was recorded and percentage of inhibition was calculated (Bors, 1992). Antioxidant status was determined based on the $\mathrm{IC}_{50}$ value using the linear equation between sample concentration (axis value) and percentage of inhibition (ordinate value).

\subsubsection{Nutrition facts and dietary element of wet spinach noodles}

WSN nutrition facts measured in this study were fat, saturated fat, protein, carbohydrate, dietary fibre, sugar, cholesterol, sodium, and energy. Fat content was determined by the Soxhlet method (AOAC, 1999). Determination of saturated fat by using packed column gas-liquid chromatography (Rader et al., 1995). Protein content was analysed by the Kjeldahl method (AOAC, 1999). Carbohydrate content was analysed by using a phenol-sulphuric acid method in microplate format (Masuko et al., 2015). Dietary fibre was measured by the gravimetric method (Kirk, 1991). Sugar content was determined by the colourimetric method (Buysse and Merckx, 1993). Cholesterol content was measured by a modified saponification process (Stewart et al., 1992). The energy amount was calculated by using Atwater System (Southgate DAT, 2013). 
Sodium, iron, magnesium, and vitamin $\mathrm{C}$ as dietary elements analysed in this study were determined through atomic spectroscopic analysis (Bader and Zimmermann, 2012) and high-performance liquid chromatography (Sánchez-Mata et al., 2000).

\subsubsection{Sensory and hedonic of wet spinach noodles}

For sensory evaluation, wet noodle samples were prepared by boiling using mineral water for the optimum cooking time. Sensory properties tests were performed by 25 semi-trained panellists to measure the acceptance and preference of four treatments of wet noodles based on the sensory attribute such as texture, colour, aroma, and hedonic. This test was done by giving scale values for texture (1-4 = stickiness - smoothness), colour (1-4 = yellowish-greeny), aroma (noodle typical-spinach typical), hedonic (1-4 = dislike-like). The questionnaire sheet was provided to panellists as a medium for giving assessments on products based on their code randomly.

\subsection{Statistical analysis}

Parametric data were analysed by One-way ANOVA to identify the existence of differences between the control and treatment groups caused by SE treatments. Analysis was continued by post hoc Duncan multiple range tests when significantly results were apparent. Nonparametric data were analysed using the Kruskal Wallis test. If there were real differences in results between control and treatment groups, the data would then be further analysed using the Mann Whitney U test.

\section{Results and discussion}

Previous research reported that spinach as one of the green vegetables rich in antioxidants and fibre proved to be a potential for food fortification in an effort to develop instant noodles as a high nutritional value food product (Ramu et al., 2016). Flour in the noodle dough was substituted by pasta spinach could obtain the nutrient-rich dry instant noodles with green colour that was very acceptable to panellists in hedonic tests. However, the use of spinach in the form of pasta in large proportions, although it had a positive impact on the characteristics of noodles chemically, but physically caused a dark green appearance on the colour of instant noodles produced, so it was less accepted by panellists. Recent study performs SE as a natural fortification in the noodle dough produce the effort to develop functional noodle products. Fortification of SE will be evaluated for its effect on antioxidant status, nutrient content, and sensory characteristics of spinach noodles produced.

\subsection{Antioxidant status of wet spinach noodles}

The antioxidant status of spinach noodles in this study was expressed in the $\mathrm{IC}_{50}$ value (Figure 3 ). This value describes a certain concentration needed by a compound to reduce $50 \%$ of free radical activity in a substance with the result that the smaller $\mathrm{IC}_{50}$ value, the stronger antioxidant activity. DPPH as a free radical will be bound by the antioxidant compound contained in the sample. In this study, the antioxidant activity of the wet noodles produced increased with the increasing concentrations of SE added to the noodles. SE fortification in the process of noodles production proved to be able to increase the antioxidant status of the final product from weak $\left(\mathrm{IC}_{50}=150.56 \mu \mathrm{g} / \mathrm{mL}\right)$ become strong $\left(\mathrm{IC}_{50}=55.25 \mu \mathrm{g} / \mathrm{mL}\right)$. As previously reported by Molyneux (2004), a substance/compound based on its activity in binding to free radicals can be classified as a very strong antioxidant compound $\left(\mathrm{IC}_{50} \leq 50 \mu \mathrm{g} / \mathrm{mL}\right)$, strong $\left(\mathrm{IC}_{50}=50-100 \mu \mathrm{g} / \mathrm{mL}\right)$, moderate $\left(\mathrm{IC}_{50}=\right.$ $100-150 \mu \mathrm{g} / \mathrm{mL})$, and weak $\left(\mathrm{IC}_{50}=151-200 \mu \mathrm{g} / \mathrm{mL}\right)$.

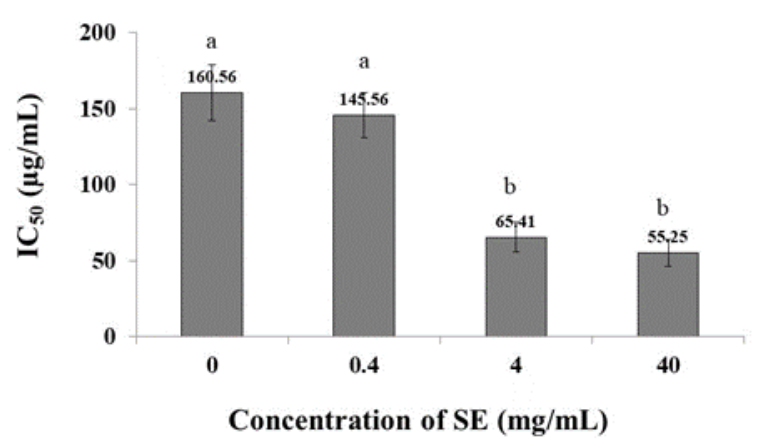

Figure 3. Antioxidant status of wet noodles that were fortified by $\mathrm{SE}$ in indicated concentration. $\mathrm{IC}_{50}$ values are presented as mean \pm SD. Bars with different notations are significantly different between treatment groups.

Enhancement of antioxidant status on the product along with the increasing level of SE added to the noodle dough proved that SE contains antioxidant compounds which have the potential as food fortification (Figure 3). Spinach has been known to possess antioxidant activity with an $\mathrm{IC}_{50}$ value of $29.67 \mu \mathrm{g} / \mathrm{mL}$ (Jung et al., 2013). Based on the $\mathrm{IC}_{50}$ value, spinach was one type of vegetable with a very strong antioxidant (Koh et al., 2012). Phenolic such as flavonoids $(2.83 \mathrm{mg} / \mathrm{kg} \mathrm{FW})$ and vitamin C (42 mg/kg FW) are compounds responsible for the antioxidant activity of the spinach (Koh et al., 2012).

Among other natural antioxidants, phenolic compounds were the most trustworthy efficacy for preventing various degenerative cases such as cardiovascular disease (Bunea et al., 2008). The efficacy was caused by the action of phenolic which can prevent the oxidation of LDL-lipoprotein, platelet aggression and damage of red blood cells (Lima et al., 2014). Meanwhile, vitamin C (ascorbic acid) is an antioxidant whose role is more dominant as an immune system stimulant (Hajian, 2016). So far, utilization of spinach as 
a fortificant in noodles was still limited to its fibre value, while its role as food fortificant with antioxidant properties has not been developed yet (Jovanovski et al., 2015; Ramu et al., 2016). With extraction technology using $70 \%$ ethanol, it allows flavonoids and vitamin $\mathrm{C}$ in spinach to be optimally contained in the extracts and its final products when SE was used as a natural fortificant rich in antioxidants (Jung et al., 2013). The existence of flavonoids and vitamin $\mathrm{C}$ as a stable compound in SE can be confirmed well because of the solubility of these two compounds in polar solvents such as ethanol and water (Jurasekova et al., 2014). Between the flavonoids and vitamin $\mathrm{C}$, which compounds are the most dominant contributing as antioxidants in SE, they have not been clearly reported. Although the content of vitamin $\mathrm{C}$ in spinach is 14 times higher than flavonoids, the stability at the cooking temperature is much lower (Pavlovska and Tanevska, 2013). Based on these facts, it was suggested that flavonoids were the main contributor to the antioxidant activity possessed by WSN. Chemically, the flavonoids in SE will be able to fuse with the proteins contained in the noodle dough through the bound between the hydroxyl group and carbon atoms in the amino acids as protein composer, which enriches the antioxidant activity of WSN produced. Without SE in the control treatment as shown in Figure 3, the final product obtained still showed antioxidant activity even though it was the weakest antioxidant status among the products of other treatments in this study.

The presence of antioxidant activity in control noodles was due to protein from wheat flour that underwent denaturation processes in tertiary structures of amino acids in order to increase the accessibility of residues in binding free radicals (Elias et al., 2008). The antioxidant status of WSN in this study showed that SE fortification in the dough for making wet noodles improved the antioxidant status of the final product. Thus, SE was very potential as a source of natural antioxidants in an effort to develop products from conventional noodles to antioxidant-rich functional noodles. However, the role of spinach noodles as functional noodles still required further analysis in both pre-clinical and clinical studies.

\subsection{Nutrition facts of wet spinach noodles}

SE fortification in this study besides being able to improve the antioxidant status of the final product, also significantly affected several types of nutrients which ultimately changed the nutrition fact of wet noodles. The nutrition fact of WSN was different from the conventional noodle, wherein the protein, cholesterol and total energy content were lower but higher in sugar content with optimal SE fortification were achieved in 4 $\mathrm{mg} / \mathrm{mL}$ concentration (Table 1). Increasing in sugar content in the product was caused by the sugar content in spinach which is around $1.7 \%$. Sugar is a soluble substance in polar solvents including water and ethanol. The technique of spinach extraction used $70 \%$ ethanol solvent, which made it possible for the sugar component to be in the filtrate or SE. That is the reason why the increased sugar content of the product was proportional to the SE fortification level (Table 1).

Data on the protein content of WSN in this study was different from previous studies. The noodle dough was added with spinach paste produced instant noodle products with a higher protein content (Ramu et al., 2016). It was known that spinach is a green vegetable with a $3.5 \%$ protein content. Therefore, the spinach paste substitution in the noodle-making process caused the increase of total protein in the final product. In this study application of spinach in noodles' fortification was performed in extract form. SE contained active compounds that are more concentrated than spinach paste which is rich in protein. Therefore, the application of SE as a food fortificant produced WSN with lower protein levels. In this study, the protein content of WSN tended to decrease along with the increasing SE levels in the dough (Table 1). Fortification of noodles with SE increased phenolic compounds of WSN whose manifestations were the stronger antioxidant status (Figure 3) due to the interaction between flavonoids and wheat flour proteins built a complex bond (Świeca et al., 2013). Antioxidant capacity of SE affected the noodle's protein denaturation. Most of the protein molecules were precipitated and slightly dissolved (Świeca et al., 2013). The small amount of dissolved protein will be measured as the protein content in the food products (Larsen et al., 2010). Based on that phenomenon, WSN in this study contains lower levels of protein than controls.

Meanwhile, the low cholesterol level of WSN in this study was caused by the carbonyl group on flavonoids in the SE fortification that bind the hydroxyl group of cholesterol to form hydrogen bonds that generated the amount of free cholesterol (Burke et al., 1974). In previous studies, it was proven that the flavonoid compounds contained in leaf extract can reduce cholesterol levels in vitro (Anggraini et al., 2018). Free cholesterol was measured as cholesterol levels of WSN were getting lower along with increasing fortification of SE levels into the noodles (Table 1). Low levels of protein and cholesterol in WSN affected the total energy of the product. Food products with low total energy levels have been widely used as diets in the overweight reducing program. The nutrition fact of WSN showed SE potentially become food fortificant for producing a promising functional noodle in the future.

Moreover, in this study, the greater potency of WSN 
Table 1. Basic nutrition values of different concentration of SE fortified noodle (amount per $100 \mathrm{~g}$ of cooked wet noodles)

\begin{tabular}{lcccc}
\hline \multirow{2}{*}{ Kind of nutrient } & \multicolumn{4}{c}{ Concentration of Spinach Extract $(\mathrm{mg} / \mathrm{mL})$} \\
\cline { 2 - 5 } & 0 & 0.4 & 4 & 40 \\
\hline Fat (g) & $2.21 \pm 0.55$ & $2.15 \pm 0.85$ & $2.08 \pm 0.71$ & $1.982 \pm 0.65$ \\
Saturated fat (g) & $0.50 \pm 0.039$ & $0.48 \pm 0.087$ & $0.52 \pm 0.095$ & $0.45 \pm 0.079$ \\
Protein (g) & $8.78 \pm 0.87^{\mathrm{a}}$ & $4.81 \pm 0.64^{\mathrm{b}}$ & $2.51 \pm 0.54^{\mathrm{c}}$ & $1.98 \pm 0.77^{\mathrm{c}}$ \\
Carbohydrates (g) & $20.56 \pm 3.98$ & $23.21 \pm 2.87$ & $22.46 \pm 4.87$ & $23.76 \pm 2.87$ \\
Dietary fiber (g) & $1.52 \pm 0.23$ & $1.45 \pm 0.73$ & $1.75 \pm 0.63$ & $1.67 \pm 0.33$ \\
Sugar (g) & $0.51 \pm 0.07^{\mathrm{a}}$ & $0.79 \pm 0.04^{\mathrm{ab}}$ & $1.23 \pm 0.08^{\mathrm{b}}$ & $1.17 \pm 0.09^{\mathrm{b}}$ \\
Cholesterol (g) & $31.61 \pm 5.65^{\mathrm{a}}$ & $29.23 \pm 4.81^{\mathrm{a}}$ & $15.24 \pm 7.71^{\mathrm{b}}$ & $14.48 \pm 3.31^{\mathrm{b}}$ \\
Sodium (g) & $4.61 \pm 0.45$ & $5.29 \pm 0.61$ & $6.78 \pm 0.67$ & $14.48 \pm 3.31$ \\
Energy amount (calories) & $136.25 \pm 12.12^{\mathrm{a}}$ & $131.98 \pm 11.72^{\mathrm{a}}$ & $123.12 \pm 22.12^{\mathrm{b}}$ & $120.75 \pm 21.17^{\mathrm{b}}$ \\
\hline
\end{tabular}

Values are presented as mean \pm standard deviation. Values with different superscript within in the same column are significantly different among the levels of treatment $(\mathrm{P}<0.05)$.

as functional noodles was supported by the existence of data about the increasing content of trace elements in products including iron, magnesium and vitamin $\mathrm{C}$ (Table 2). The addition of maximum concentrations of SE $(40 \mathrm{mg} / \mathrm{mL})$ in this study significantly produced products with a higher vitamin $\mathrm{C}$ content (Table 2) although there was no significant enhancement in antioxidant activity (Figure 3). This fact further reinforced the notion that flavonoids are the main contributor to the antioxidant activity of spinach noodles. However, the elucidation about this fact still needs further study. For other trace elements such as magnesium and iron, as well as antioxidant activity, the optimum level of WSN was achieved by a concentration of $4 \mathrm{mg} / \mathrm{mL}$ (Table 2). Magnesium has an important role in more than 300 biological processes that occur in the body, including digestion, communication between nerve cells, and the movement of muscles while the iron together with protein plays in enzyme construction in order to supply the energy inside the body cells (Prashanth et al., 2015).

\subsection{Sensory characteristic of spinach extract fortified wet noodles}

WSN as the final product of SE fortification had chemical characteristics that support the expected functional properties. However, as a product with potency as a functional food, the excellence of chemical aspects must also be strengthened by its sensory characteristics. Besides sufficiently fulfilling the good efficacy requirements related to the food-specific for health used, a functional food product should show a fairly good level in acceptance of its consumers (Martirosyan and Singh, 2015). Previous research demonstrated that medium level of substitution with spinach paste in instant noodles showed a good panellist preference for some sensory attributes such as colour, texture, taste, flavour, and overall, although at the maximum level of substitution the panellist's acceptance was less satisfactory as a result of the declining colour attribute (Ramu et al., 2016). The maximum substitution level of spinach paste obtained the dark green noodle which is visually less attractive (Figure 4). Through extraction technology, spinach in this study was very possible for its application as food fortification because the quantity of its additions was relatively less than spinach paste. The optimum level of fortification to produce spinach noodles with a fairly soft texture and greenish colour was achieved at a concentration of $4 \mathrm{mg} /$ $\mathrm{mL}$. Overall, all the sensory attributes of WSN including a fairly soft texture, greenish colour, and the distinctive aroma of spinach can be accepted by the panellists with a better level of preference were achieved in the SE fortification up to $4 \mathrm{mg} / \mathrm{mL}$ in the noodle dough (Table $3)$. The acceptance level of maximum $(40 \mathrm{mg} / \mathrm{mL})$ was equal to optimum SE fortification. Thus, the application of $\mathrm{SE}$ as food fortificant produced the final product that is more acceptable than spinach paste. It was suggested SE is a potential food fortificant for antioxidant enrichment in future functional food.

Table 2. Dietary elements of different concentration of SE fortified noodle (amount per $100 \mathrm{~g}$ of cooked wet noodles)

\begin{tabular}{ccccc}
\hline \multirow{2}{*}{ Elements } & \multicolumn{4}{c}{ Concentration of Spinach Extract $(\mathrm{mg} / \mathrm{mL})$} \\
\cline { 2 - 5 } & 0 & 0.4 & 4 & 40 \\
\hline Iron (mg) & $1.61 \pm 0.32^{\mathrm{a}}$ & $2.44 \pm 0.38^{\mathrm{a}}$ & $4.21 \pm 0.72^{\mathrm{b}}$ & $3.87 \pm 0.48^{\mathrm{ab}}$ \\
Magnesium (mg) & $19.61 \pm 3.87^{\mathrm{a}}$ & $22.38 \pm 7.38^{\mathrm{a}}$ & $98.83 \pm 8.97^{\mathrm{b}}$ & $102.63 \pm 0.25^{\mathrm{b}}$ \\
Vitamin C (mg) & $0.12 \pm 0.018^{\mathrm{a}}$ & $0.82 \pm 0.027^{\mathrm{a}}$ & $2.31 \pm 0.42^{\mathrm{b}}$ & $15.56 \pm 4.81^{\mathrm{c}}$ \\
\hline
\end{tabular}

Values are presented as mean \pm standard deviation. Values with different superscript within in the same column are significantly different among the levels of treatment $(\mathrm{P}<0.05)$. 
Table 3. Sensory characteristic of noodle fortified with various concentrations of SE

\begin{tabular}{cccccc}
\hline \multirow{2}{*}{ Sensory criteria } & \multicolumn{3}{c}{ Concentration of SE $(\mathrm{mg} / \mathrm{mL})$} & \multirow{2}{*}{ Score criteria } \\
\cline { 2 - 5 } & 0 & 0.4 & 4 & 40 & $1-4$ (stickiness-smoothness) \\
Texture & $2.20 \pm 0.66^{\mathrm{a}}$ & $2.50 \pm 0.57^{\mathrm{b}}$ & $2.73 \pm 0.64^{\mathrm{bc}}$ & $2.77 \pm 0.62^{\mathrm{c}}$ & $1-4$ (yellow-green) \\
Colour & $1.10 \pm 0.40^{\mathrm{a}}$ & $1.27 \pm 0.52^{\mathrm{b}}$ & $2.40 \pm 0.49^{\mathrm{bc}}$ & $3.37 \pm 0.49^{\mathrm{bc}}$ & (noodle typical-spinach typical) \\
Aroma & $1.12 \pm 0.35^{\mathrm{a}}$ & $1.33 \pm 0.47^{\mathrm{ab}}$ & $2.63 \pm 0.69^{\mathrm{bc}}$ & $3.50 \pm 0.73^{\mathrm{bc}}$ & $1-4$ (dislike-like) \\
Hedonic & $2.17 \pm 0,83^{\mathrm{a}}$ & $2.47 \pm 0.68^{\mathrm{a}}$ & $2.83 \pm 0.64^{\mathrm{b}}$ & $2.73 \pm 0.94^{\mathrm{b}}$ & $1-4$ (dike
\end{tabular}

Values are presented as mean \pm standard deviation. Values with different superscript within in the same column are significantly different among the levels of treatment $(\mathrm{P}<0.05)$.

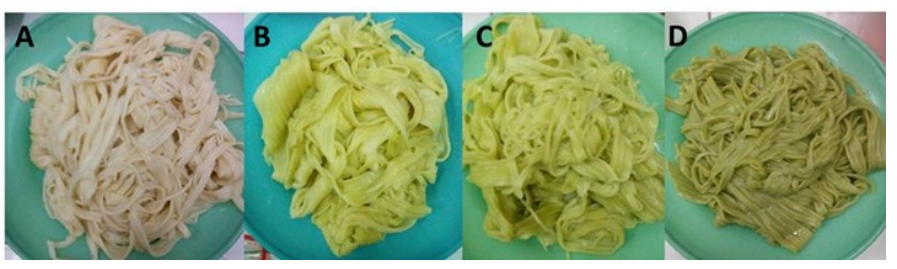

Figure 4. Colour attribute of sensory characteristic on WSN. A, B, C, and D mean yellow, rather green (bright green), fairly green (pretty green), and green respectively.

\section{Conclusion}

Fortifying noodle by SE produced antioxidant rich, low calorie, and preferable-WSN. The SE concentration of $4 \mathrm{mg} / \mathrm{mL}$ was determined as the fortification optimum level. WSN was expected as a promising functional noodle in the future.

\section{Acknowledgements}

This work was funded by the Faculty of Animal Science and Agriculture through the Non-Tax Revenue.

\section{References}

Anggraini, D.I. and Lili, F.N. (2018). Activity Test of suji leaf extract (Dracaena angustifolia Roxb.) on in vitro cholesterol lowering. Journal of Scientific and Applied Chemistry, 21(2), 54-58. https:// doi.org/10.14710/jksa.21.2.54-58

AOAC (Association of Official Analytical Chemists) (1999). Official Methods of Analysis. Washington DC, USA: AOAC.

Ashor, A.W., Siervo, M. and Mathers J.T. (2016). Chapter 43 - Vitamin C, Antioxidant Status, and Cardiovascular Aging. In Malavolta, M. and Mocchegiani, E. (Eds.) Molecular Basis of Nutrition and Aging. A Volume in the Molecular Nutrition Series. Vol. 1, p. 609-619. USA: Academic Press. https://doi.org/10.1016/B978-0-12-801816-3.000431

Babu, N.G.R., Divakar, J., Krishna, U.L. and Vigneshwaran, C. (2018). Study of antimicrobial, antioxidant, Anti-inflammatory activities and phytochemical analysis of cooked and uncooked different spinach leaves. Journal of Pharmacognosy and Phytochemistry, 7(5), 1798-1803.
Bader, N.R. and Zimmermann, B. (2012). Sample preparation for atomic spectroscopic analysis: An overview. Advances in Applied Science Research, 3 (3), 1733-1737.

Bergman M., Varshavsk, L., Gottlieb, H.E. and Grossman, S. (2001). The antioxidant activity of aqueous spinach extract: chemical identification of active fractions. Journal of Phytochemistry, 58(1), 143-152. https://doi.org/10.1016/S0031-9422(01) 00137-6

Bors, W., Saran, M. and Elstner, E.F. (1992). Screening for plant anti-oxidants. In Linskens, H.F. and Jackson, J.F. (Eds). Modern Methods of Plant Analysis-Plant Toxin Analysis-New Series. Vol 13, p. 277-295. Berlin: Springer. https:// doi.org/10.1007/978-3-662-02783-7_11

Bunea, A., Andjelkovic, M., Socaciu, C., Bobis, O., Neacsu, M., Verhe, R. and Camp J.V. (2008). Total and individual carotenoids and phenolic acids content in fresh, refrigerated and processed spinach (Spinacia oleracea L.). Journal of Food Chemistry, 108(2), 649-656. https://doi.org/10.1016/ j.foodchem.2007.11.056

Burke R.W., Diamondstone, B.I., Velapoldi, R.A. and Menis, O. (1974). Mechanisms of the LiebermannBurchard and Zak color reactions for cholesterol. Clinical Chemistry, 20(7), 794-801. https:// doi.org/10.1093/clinchem/20.7.794

Buysse, J.A.N. and Merckx, R. (1993). An improved colorimetric method to quantify sugar content of plant tissue. Journal of Experimental Botany, 44(10), 1627-1629. https://doi.org/10.1093/jxb/44.10.1627

Chung C.E., Lee, K.W. and Cho, M.S. (2010). Effect of Ramyen and Noodles Intake in Diet and Health Status of Koreans. Journal of the Korean Society of Food Culture, 25(2), 109-116

Elias R.J., Kellerby, S.S. and Decker, E.A. (2008). Antioxidant activity of proteins and peptides. Critical Review in Food Science and Nutrition, 48 (5), 430-441. https:// doi.org/10.1080/10408390701425615

Errington, F., Gewertz, D. and Fujikura, T. (2013). The noodle narratives: The global rise of an industrial food into the twenty-first century. USA: University 
of California Press. https:// doi.org/10.1525/9780520956674

Gulia, N., Dhaka, V. and Khatkar, B.S. (2014). Instant noodles: processing, quality, and nutritional aspects. Critical Reviews in Food Science and Nutrition, 54(10), 1386-1399. https:// doi.org/10.1080/10408398.2011.638227

Hajian, S. (2016). Positive effect of antioxidants on immune system. Immunopathologia Persa, 1(1), 1-2.

Hou, G.G. (2010). Asian noodles: Science, Technology, and Processing. United Kingdom: John Wiley and Sons. https://doi.org/10.1002/9780470634370

Jovanovski, E., Bosco, L., Khan, K., Au-Yeung, F., Ho, H., Zurbau, A. and Vuksan, V. (2015). Effect of spinach, a high dietary nitrate source, on arterial stiffness and related hemodynamic measures: a randomized, controlled trial in healthy adults. Clinical Nutrition Research, 4(3), 160-167. https://doi.org/10.7762/cnr.2015.4.3.160

Jung, L.S., Lee, S.H., Kim, S. and Ahn, J. (2013). Effect of high hydrostatic pressure on the quality-related properties of carrot and spinach. Food Science and Biotechnology, 22(1), 189-195. https:// doi.org/10.1007/s10068-013-0066-0

Jurasekova, Z., Domingo, C., García-Ramos, J.V. and Sánchez-Cortés, S. (2014). Effect of $\mathrm{pH}$ on the chemical modification of quercetin and structurally related flavonoids characterized by optical (UVvisible and Raman) spectroscopy. Physical Chemistry Chemical Physics, 16(25), 12802-12811. https://doi.org/10.1039/C4CP00864B

Kirk, R.S. (1991). Pearson's Composition and Analysis of Foods. Singapore: Longman Singapore Publishers

Koh, E., Charoenprasert, S. and Mitchell, A.E. (2012). Effect of organic and conventional cropping systems on ascorbic acid, vitamin $\mathrm{C}$, flavonoids, nitrate, and oxalate in 27 varieties of spinach (Spinacia oleracea L.). Journal of Agricultural and Food Chemistry, 60 (12), 3144-3150. https://doi.org/10.1021/jf300051f

Larsen, T.M., Dalskov, S.M., van Baak, M., Jebb, S.A., Papadaki, A., Pfeiffer, A.F. and Astrup, A. (2010). Diets with high or low protein content and glycemic index for weight-loss maintenance. New England Journal of Medicine, 363(22), 2102-2113. https:// doi.org/10.1056/NEJMoa1007137

Lima, G.P.P., Vianello, F., Corrêa, C.R., Campos, R.A.D.S. and Borguini, M.G. (2014). Polyphenols in fruits and vegetables and its effect on human health. Food and Nutrition Sciences, 5(11), 10651082. https://doi.org/10.4236/fns.2014.511117

Martirosyan, D.M. and Singh, J. (2015). A new definition of functional food by FFC: what makes a new definition unique? Functional Foods in Health and Disease, 5(6), 209-223. https://doi.org/10.31989/ ffhd.v5i6.183

Masuko, T., Minami, A., Iwasaki, N., Majima, T., Nishimura, S.I. and Lee, Y.C. (2005). Carbohydrate analysis by a phenol-sulfuric acid method in microplate format. Analytical Biochemistry, 339(1), 69-72. https://doi.org/10.1016/j.ab.2004.12.001

Molyneux, P. (2004). The use of the stable free radical diphenylpicrylhydrazyl (DPPH) for estimating antioxidant activity. Songklanakarin Journal Science Technology, 26(2), 211-219.

Naznin, M.T., Lefsrud, M., Gravel, V. and Azad, M.O.K. (2019). Blue light added with red LEDs enhance growth characteristics, pigments content, and antioxidant capacity in lettuce, spinach, kale, basil, and sweet pepper in a controlled environment. Plants, 8(4), 93. https:// doi.org/10.3390/plants8040093

O'Dea, J.A. (2003). Why do kids eat healthful food? Perceived benefits of and barriers to healthful eating and physical activity among children and adolescents. Journal of the American Dietetic Association, 103(4), 497-501. https:// doi.org/10.1016/S0002-8223(03)00013-0

Pavlovska, G. and Tanevska, S. (2013). Influence of temperature and humidity on the degradation process of ascorbic acid in vitamin $\mathrm{C}$ chewable tablets. Journal of Thermal Analysis and Calorimetry, 111(3), 1971-1977. https:// doi.org/10.1007/s10973-011-2151-z

Prashanth, L., Kattapagari, K.K., Chitturi, R.T., Baddam, V.R.R. and Prasad, L.K. (2015). A review on role of essential trace elements in health and disease. Journal of Dr NTR University of Health Sciences, 4(2), 75. https://doi.org/10.4103/22778632.158577

Rader, J.I., Angyal, G., O'Dell, R.G., Weaver, C.M., Sheppard, A.J. and Bueno, M.P. (1995). Determination of total fat and saturated fat in foods by packed column gas-liquid chromatography after acid hydrolysis. Food Chemistry, 54(4), 419-427. https://doi.org/10.1016/0308-8146(95)00054-M

Ramu, L., Jyotikiran, Maloo, S. and Ramugolla. (2016). Physical, chemical and sensory properties of spinach paste fortified instant noodles. International Journal of Innovative Technology and Research, 4(6), 53185322.

Roberts, J.L. and Moreau, R. (2016). Functional properties of spinach (Spinacia oleracea L.) phytochemicals and bioactives. Food and Function, 7(8), 3337-3353. https://doi.org/10.1039/ 


\section{C6FO00051G}

Sánchez-Mata, M.C., Cámara-Hurtado, M., DíezMarqués, C. and Torija-Isasa, M.E. (2000). Comparison of high-performance liquid chromatography and spectrofluorimetry for vitamin $\mathrm{C}$ analysis of green beans (Phaseolus vulgaris L.). European Food Research and Technology, 210 (3), 220-225. https://doi.org/10.1007/PL00005516

Shin, H.Y. and Kang, H.T. (2017). Recent trends in the prevalence of underweight, overweight, and obesity in Korean adults: the Korean National Health and Nutrition Examination Survey from 1998 to 2014. Journal of Epidemiology, 27(9), 413-419. https://doi.org/10.1016/j.je.2016.08.014

Southgate, D.A.T. (2013). Food Composition Tables. In Caballero, B. (Ed.) Encyclopedia of Food Sciences and Nutrition, p. 2599-2606. USA: Academic Press. https://doi.org/10.1016/B0-12-227055-X/00504-6

Stewart, G., Gosselin, C. and Pandian, S. (1992). Selected ion monitoring of tert-butyldimethylsilyl cholesterol ethers for determination of total cholesterol content in foods. Food Chemistry, 44(5), 377-380. https://doi.org/10.1016/0308-8146(92) 90271-3

Świeca, M., Gawlik-Dziki, U., Dziki, D., Baraniak, B. and Czyż, J. (2013). The influence of proteinflavonoid interactions on protein digestibility in vitro and the antioxidant quality of breads enriched with onion skin. Food Chemistry, 141(1), 451-458. https://doi.org/10.1016/j.foodchem.2013.03.048 